PREPARED FOR THE U.S. DEPARTMENT OF ENERGY, UNDER CONTRACT DE-AC02-76CH03073

PPPL-3657

PPPL-3657

UC-70

Upgrade to the Tritium Remote Control and Monitoring System for TFTR D\&D

by

P. Sichta, G. Oliaro, and S. Sengupta

January 2002

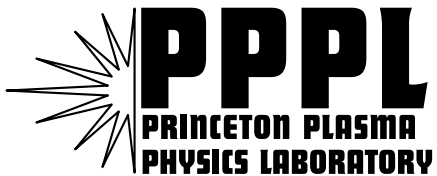

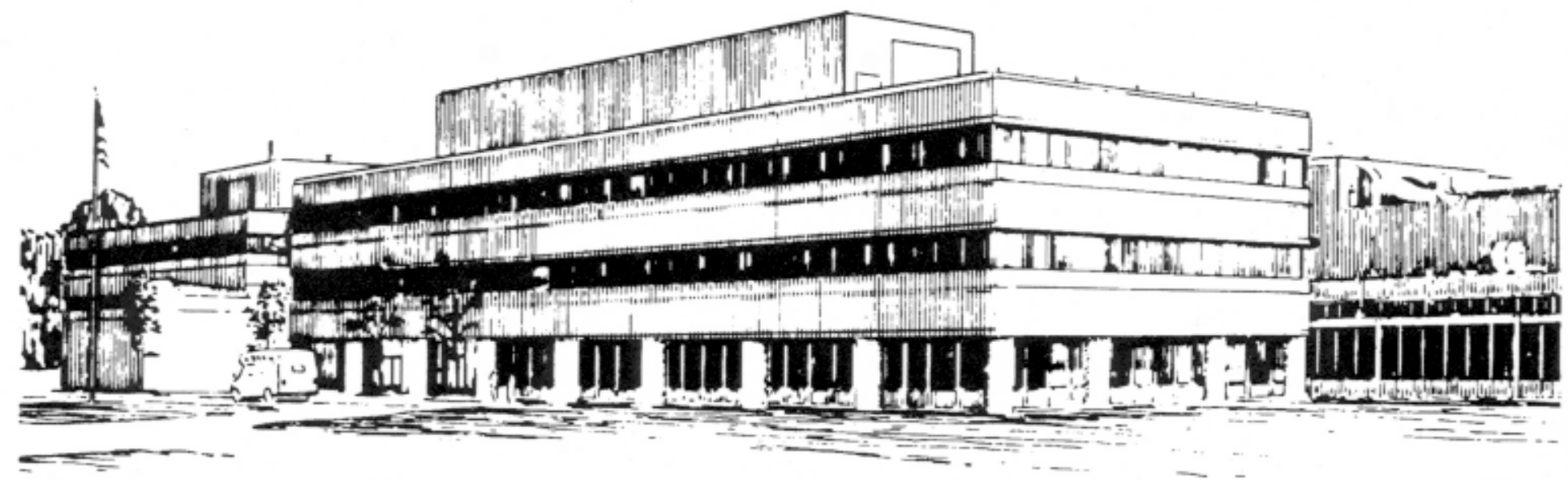

PRINCETON PLASMA PHYSICS LABORATORY PRINCETON UNIVERSITY, PRINCETON, NEW JERSEY 


\section{PPPL Reports Disclaimer}

This report was prepared as an account of work sponsored by an agency of the United States Government. Neither the United States Government nor any agency thereof, nor any of their employees, makes any warranty, express or implied, or assumes any legal liability or responsibility for the accuracy, completeness, or usefulness of any information, apparatus, product, or process disclosed, or represents that its use would not infringe privately owned rights. Reference herein to any specific commercial product, process, or service by trade name, trademark, manufacturer, or otherwise, does not necessarily constitute or imply its endorsement, recommendation, or favoring by the United States Government or any agency thereof. The views and opinions of authors expressed herein do not necessarily state or reflect those of the United States Government or any agency thereof.

\section{Availability}

This report is posted on the U.S. Department of Energy's Princeton Plasma Physics Laboratory Publications and Reports web site in Fiscal Year 2002. The home page for PPPL Reports and Publications is: http://www.pppl.gov/pub_report/

DOE and DOE Contractors can obtain copies of this report from:

U.S. Department of Energy

Office of Scientific and Technical Information

DOE Technical Information Services (DTIS)

P.O. Box 62

Oak Ridge, TN 37831

Telephone: (865) 576-8401

Fax: (865) 576-5728

Email: reports@adonis.osti.gov

This report is available to the general public from:

National Technical Information Service

U.S. Department of Commerce

5285 Port Royal Road

Springfield, VA 22161

Telephone: 1-800-553-6847 or

(703) 605-6000

Fax: (703) 321-8547

Internet: http://www.ntis.gov/ordering.htm 


\title{
Upgrade to the Tritium Remote Control and Monitoring System for TFTR D\&D
}

\author{
*P. Sichta, G. Oliaro, S. Sengupta \\ Princeton Plasma Physics Laboratory, P.O. Box 451, Princeton, New Jersey 08543
}

\begin{abstract}
Since 1988, the Tritium Remote Control and Monitoring System (TRECAMS)[1] has performed crucial functions in support of D-T operations of the Tokamak Fusion Test Reactor (TFTR) [2] at the Princeton Plasma Physics Laboratory (PPPL). Although plasma operations on TFTR were completed in 1997, the need for TRECAMS continued. During this period TRECAMS supported the TFTR tritium systems, the TFTR's Shutdown and Safing phase, and the TFTR Decontamination and Decommissioning (D\&D) project. The most critical function of the TRECAMS in the post-TFTR era has been to provide a real-time indication of the airborne tritium levels in the tritium areas and the (HVAC) stacks. TRECAMS is a critical tool in conducting safe TFTR D\&D tritium-line breaks and other tritium-related work activities. Beginning in 1998, the failure rate of the system's hardware sharply increased. Furthermore, the specialized knowledge required to maintain the original software and hardware was diminishing. It soon became apparent that a failure of the TRECAMS could significantly impact the TFTR D\&D project's cost and schedule. To preclude this, the TRECAMS hardware and software was upgraded in the year 2000 to use modern components. This paper will describe that successful upgrade, including a review of the engineering processes and our operating experiences with the upgraded system.
\end{abstract}

\section{INTRODUCTION}

The TRECAMS project began in 1986 in support of the TFTR's Deuterium-Tritium (D-T) experimental operations. The system offered a good balance of "tried-and-true" and leadingedge hardware and software technology. TRECAMS was used to facilitate the operations of tritium system operators, TFTR operations supervisors, and HVAC operators. Following the cessation of TFTR operations, the system's functions were still required, albeit with a different emphasis. Rather than facilitating the fueling of TFTR with tritium the system was now essential for tritium removal from TFTR and its subsystems. In D\&D terminology, a 'line break' is a carefully planned and executed engineering activity in which tritiumcontaining structures are physically separated. A line break will release tritium in a controlled manner. TRECAMS provides a real-time indication of the amount of tritium that is being released during a line break. In addition to displaying and archiving the data, site supervisors can ensure that the line break procedure is exhibiting the expected tritium release behavior. This real-time monitoring capability has made TRECAMS a critical system for the D\&D project.

\section{A. The D/3 System}

A D/3 system has three major hardware components, the Display Control Module (DCM), the Process Control Module (PCM), and the Operator Control Module (OCM). The components communicate using a standard TCP/IP network.

An OCM provides the operator interface and is an off-the-shelf PC that is running Microsoft's NT-workstation operating system. The PCM is a rack-mountable single board computer that resides in a MultibusII-like card cage. It is used for realtime process control. It includes a Pentium CPU running a proprietary real-time operating system kernel. A communications cable connects the PCM with several I/O multiplexor chassis that contain I/O modules that interface with the field instruments and controllers. The PCM provides a runtime database that contains the I/O attributes, process control logic, and process alarm attributes. The DCM provides high-level process-control functions, such as periodic data trending, data archiving, alarm collection, and special functions needed to support the system configuration. This is also an offthe-shelf PC that is running Microsoft's NT-Server operating system. The DCM is also used as a software development platform that is used for creating and managing the operator displays and editing the process-control database.

\section{RELIABILITY PROBLEMS}

The TRECAMS performed admirably throughout TFTR's D-T experimental operations. During this period the D/3 hardware and software product line continued to rapidly evolve. Although advanced D/3 technologies were commercially available, the TRECAMS was not upgraded in order to maximize availability and reliability, and to minimize the costs associated with engineering changes. This philosophy was effective, but helped contribute to the TRECAMS reliability and maintainability (R\&M) problems that eventually became a concern for the D\&D project.

The R\&M issues were as diverse as they were numerous. Foremost, all of the engineering staff that had specialized D/3 and TRECAMS technical expertise were no longer employed by PPPL. A significant rise in the hardware failures rate began in 1998. Compounding this was that diagnosis was laborious. Significant engineering manpower was increasingly being diverted from other PPPL projects to service the TRECAMS, to

- Work performed under the auspices of the USDOE by Princeton Plasma Physics Laboratory under Contract No. DE-AC02$76 \mathrm{CH} 03073$. 
the detriment of the other projects. TRECAMS replacement parts were expensive to replace, in shrinking supply, and could take weeks for delivery. At the applications software level, operator-requested changes could not be made due to the absence of D/3 software expertise. Furthermore, the D/3 supplier (GSE Systems) could no longer provide effective support for the (seven versions) old software. As the calendar year 2000 approached, it was discovered that our computer hardware, commercial operating systems, and D/3 system software was not "Y2K" compatible. In the fourteen years since the acquisition of the TRECAMS, technologies that were at the time "tried-and-true" were transformed into "obsoleteand-unsupportable". A review of these R\&M issues convinced the D\&D project to upgrade the TRECAMS.

\section{THE UPGRADE}

In the latter part of calendar year 2000, the TRECAMS Upgrade project began. Obsolete hardware would be replaced, D/3 system software would be upgraded, the existing PPPLdesigned D/3 applications would be ported to run on the upgraded system, and PPPL would regain D/3 expertise through training courses. A significant portion of the engineering effort for the upgrade was subcontracted to GSE Systems to minimize the workload on PPPL engineering, and to maximize the chances for a successful upgrade by utilizing a team experienced in D/3 upgrades. PPPL engineering resources concentrated on system validation, scheduling, and managing the on-site aspects of the transition.

\section{A. Hardware}

Fig. 1 shows the upgraded TRECAMS hardware layout. Although a D/3 system architecture that retained the original system's redundancy was available, it was not purchased in order to reduce the cost and complexity of the upgrade. A redundant configuration can be added in the future if the need arises.
One of the fortunate aspects of this upgrade was that almost all of the hardware in "the field" could be reused, as-is. The new Pentium-based PCM CPU module replaced four computing boards in the old system. A GSE Systems supplied real-time operating system kernel is still in use on the PCM. The communications network was able to use the original 100 micron multimode fiber optic cables. The network equipment was capable of using the original system's (now) non-standard 100 micron fiber cable because the distances were short $(<300$ meters).

In the original system there was a specially-designed fiber optic network device that enabled the PCM to extend its I/O multiplexor chassis. Special PCM software was also required for this device. It was decided to eliminate this unique hardware and software by configuring a new PCM into the TRECAMS D/3 architecture. This PCM was locally installed in an existing chassis, near the remote I/O multiplexors,

The OCM and DCM now feature popular computing components such Microsoft's NT operating system, and Ethernet communications. Due to the popularity of these components, hardware and software obsolescence is much less of a concern than with the original system.

\section{B. Software}

The reliability of the industry-standard PC hardware, operating system, and network components of the upgraded system are well-established. There were concerns about to the new D/3 software. Would the software be reliable? Would "porting" the rather old TRECAMS-specific application software introduce a functional error? Would the process databases continue to function properly? Would the TRECAMS operators be comfortable with the upgraded operator displays? The answer to these questions follow.

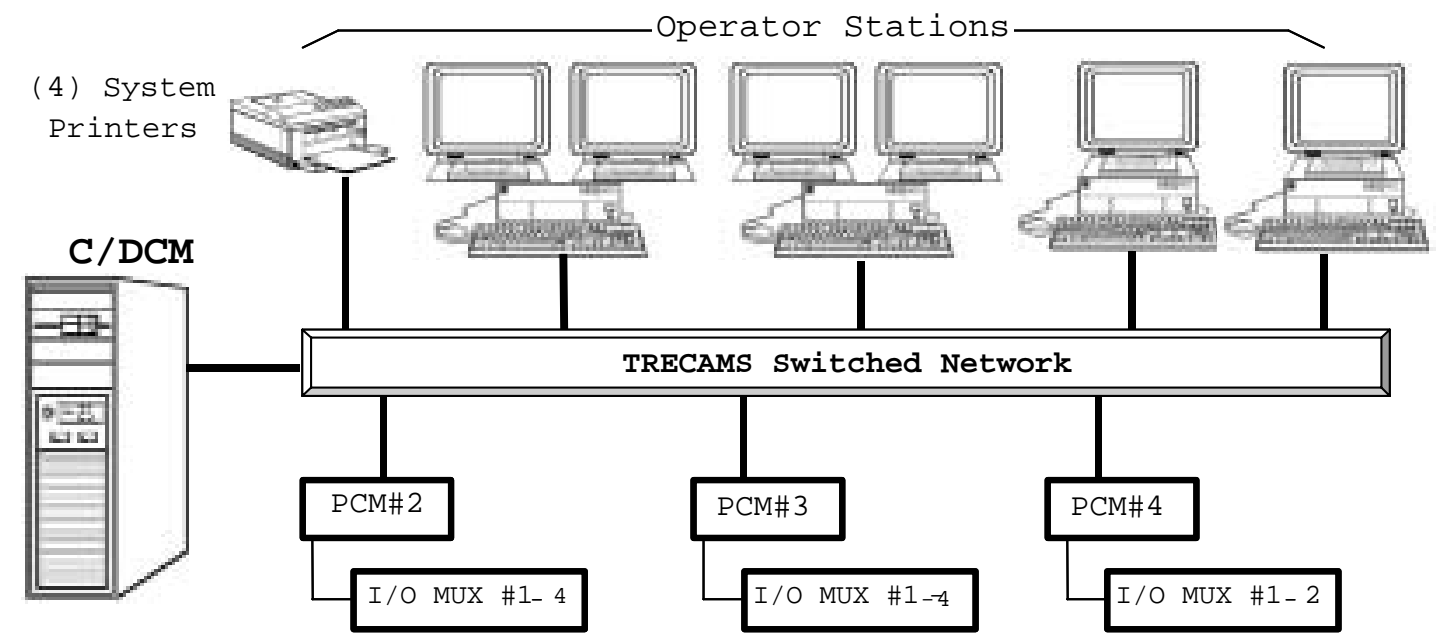

Fig. 1. Block Diagram of upgraded TRECAMS. 
The D/3 system software (version 10.1) had been released for over a year and was successfully operating under NT at several major facilities. Porting of the TRECAMS software was a major concern. This concern was alleviated to some degree because the subcontracted GSE team had experience upgrading D/3 systems. The scope of our upgrade presented no unusual challenges for them. The TRECAMS process control algorithms and I/O attributes are in a database in the PCM. The configuration of that database is contained in several ASCII (text) files. Fortunately, the format of these files remained virtually unchanged between the original version_3 and the new version_10 D/3 software. Furthermore, a utility on the original system was used to "up-load" the online database from the TRECAMS PCM memory to a file, which could then be used as a basis for building the upgraded D/3 databases.

In addition to the PCM database, another important software porting task applied to the operator's control displays. The four types of control displays used most by the TRECAMS operators are called Faceplates, Trending, Alarms, and Graphics. Similar to the PCM database, the faceplates, trending, and alarm displays were configured using ASCII files. Again, these files were capable of being copied from the version_3 system and modified for use on the upgraded version_10 software with little change.

The most difficult porting effort was for the thirteen graphics displays. The new graphics engine was completely different, and each graphics display had to be replicated in appearance and coded from scratch. Even though the new D/3 graphics system was capable of providing powerful process-related functionality and detailed graphics symbols, it was desirable to keep the display's appearance as close to the original as possible in order to minimize the imposition of the upgrade on the operators, who were accustomed to the existing displays.

\section{Operator Interface}

One of the most desirable features of the upgrade was to maintain the look and feel of the Operator Interface in both the hardware layout and the appearance of the control displays. This was critical in making the transition smooth and minimizing the impact of the upgrade on operations. The original system's operator interface consisted of a special D/3 process control keyboard, two 21-inch color displays, and a D/3 annunciator panel. The upgraded system's operator interface maintained the look and feel of the original. It consisted of a standard Compaq PC with keyboard and mouse, a dual-monitor graphics card, two 21-inch monitors, and a new D/3 process control keyboard. The special D/3 keyboard's functions can now be performed using the standard computer keyboard and mouse. As previously mentioned, the operator's Faceplates, Trending, Alarms, and Graphics displays retained their original appearance.

\section{Training}

Two types of training were included in the upgrade, corporate training and in-house training. A major goal of the upgrade was to replace PPPL's lost D/3-specific expertise to facilitate in- house software changes and effective hardware support. Early in the upgrade project several PPPL engineers attended training courses at GSE's training center. This provided immediate benefits for the upgrade project, and was actually helpful in keeping the original system running during its waning months. The training provided PPPL's TRECAMS engineers with a an understanding of the D/3 architecture and operating principals. It also helped to establish the technical dialogue between PPPL and the GSE upgrade team. Finally, the training helped in developing the detailed system validation processes and procedures.

In-house training was presented to the TRECAMS operators. This was TRECAMS-specific, hands-on training. The training's primary purpose was to introduce the new OCM equipment, explain the revised (OCM) operating procedures, and give the operators an opportunity to use the new OCM prior to deployment. The ability to maintain the original OCM's hardware configuration and software display's look-and-feel made the training go extremely well.

\section{E. Testing}

A key requirement for implementation was to avoid a significant interruption of the D\&D project and tritium operations. The project was given a two-week window to perform the upgrade and validate the upgraded TRECAMS. To achieve this, a priority was given to validate as much hardware and software as possible prior to actually installing the system at PPPL. Validation was comprised of extensive code audits, and hardware, configuration, and software tests at the GSE facility. The tests at GSE were conducted using a test procedure designed to demonstrate almost all aspects of the system. To accomplish this, the new hardware and a network was setup and operated at the GSE test facility. A test-PCM was populated with $\mathrm{I} / \mathrm{O}$ modules into which test signals could be injected to observe the propagation of alarms and processvalues to the various OCM displays and other DCM software.

After the equipment arrived at PPPL, some of the tests were duplicated prior to installation. After installation, all functions of the TRECAMS were completely tested thorough a series of Integrated Systems Test Procedures. The test went very smoothly. Critical real-time tritium monitoring functions were completely validated in a few days. Complete testing was finished in about two weeks.

\section{F. Installation}

To minimize the downtime for $\mathrm{D} \& \mathrm{D}$, the installation of the TRECAMS upgrade included pre-cutover tasks. The precutover phase began several weeks prior to the shutdown of the original D/3 system.. It included the re-termination and minor rerouting of fiber optic cables, installation of the PPPL-supplied Ethernet network equipment, and (a few days before cutover) the removal of the old OCM hardware. After only one day the PCMs, DCM, and one OCM were installed and connected to the network. All systems booted normally and the final integrated systems testing began. The remaining OCM installations were completed in a couple of days. Thorough 
planning and inter-departmental communication helped the installation to proceed without unanticipated delays or work interruption.

\section{G. Maintenance and Support}

GSE Systems offers a variety of D/3 maintenance and support plans that may include hardware, software, and design services. Because the TRECAMS project has a limited lifetime (3-5 yrs), the most modest support program was selected. The maintenance agreement provides 20 hours of technical support and software-maintenance upgrades. PPPL maintains an inhouse inventory of spare $\mathrm{D} / 3$ hardware, so hardware replacement and premium repair services were not included. In addition to the aforementioned support plan, GSE offers a complete range of training courses, such as graphics programming and hardware troubleshooting.

\section{CONCLUSION}

The TRECAMS upgrade project was a resounding success from both the management and technical viewpoints. All of the major goals were achieved on schedule and within budget. In the year since the upgrade the system's performance and reliability has been excellent. No failures have occurred. Soon after the upgrade project's completion, a few long-awaited application software changes were made. In addition, the reliability of automated report generation software has been reliable, unlike the previous software. The operators are comfortable with the system's familiar PC desktop/windowing HMI. They have shown a preference for using the standard keyboard and mouse instead of the legacy D/3 process control keyboard.
The corporate ownership of the $\mathrm{D} / 3$ product changed several times since the original PPPL procurement in 1986. A key in the success of the project was that the $D / 3$ engineering personnel remained with the product, through its revisions and corporate changes. They helped to maintain continuity in the product, to introduce evolutionary changes rather than implementing completely new methods. This has helped immensely in the areas of software porting and operator training.

\section{ACKNOWLEDGMENT}

The success of the TRECAMS upgrade would not have been possible without the contributions of many people. The subcontractors at GSE were professional and cooperative throughout the project. At PPPL, the D\&D and tritium systems management and operators were supportive in all aspects of the project, especially during the periods of testing and training. Finally, the success of the upgrade can be attributed to the original system's engineering team, who diligently leveraged PPPL's established Engineering Practices and Procedures to thoroughly document the design, test, and installation of the system. These documents were invaluable.

\section{REFERENCES}

[1] N. Arnold et al, "Distributed Process Control System for Remote Control and Monitoring of the TFTR Tritium Systems," $15^{\text {th }}$ Symposium on Fusion Technology, Utrecht, The Netherlands (1988). 


\section{External Distribution}

Plasma Research Laboratory, Australian National University, Australia

Professor I.R. J ones, Flinders University, Australia

Professor J oão Canalle, Instituto de Fisica DEQ/IF - UERJ , Brazil

Mr. Gerson O. Ludwig, Instituto Nacional de Pesquisas, Brazil

Dr. P.H. Sakanaka, Instituto Fisica, Brazil

The Librarian, Culham Laboratory, England

Library, R61, Rutherford Appleton Laboratory, England

Mrs. S.A. Hutchinson, JET Library, England

Professor M.N. Bussac, Ecole Polytechnique, France

Librarian, Max-Planck-Institut für Plasmaphysik, Germany

J olan Moldvai, Reports Library, MTA KFKI-ATKI, Hungary

Dr. P. Kaw, Institute for Plasma Research, India

Ms. P.J . Pathak, Librarian, Insitute for Plasma Research, India

Ms. Clelia De Palo, Associazione EURATOM-ENEA, I taly

Dr. G. Grosso, Instituto di Fisica del Plasma, Italy

Librarian, Naka Fusion Research Establishment, J AERI, J apan

Library, Plasma Physics Laboratory, Kyoto University, J apan

Research Information Center, National Institute for Fusion Science, J apan

Dr. O. Mitarai, Kyushu Tokai University, J apan

Library, Academia Sinica, Institute of Plasma Physics, People's Republic of China

Shih-Tung Tsai, Institute of Physics, Chinese Academy of Sciences, People's Republic of China

Dr. S. Mirnov, TRINITI, Troitsk, Russian Federation, Russia

Dr. V.S. Strelkov, Kurchatov Institute, Russian Federation, Russia

Professor Peter Lukac, Katedra Fyziky Plazmy MFF UK, Mlynska dolina F-2, Komenskeho Univerzita, SK-842 15 Bratislava, Slovakia

Dr. G.S. Lee, Korea Basic Science Institute, South Korea

Mr. Dennis Bruggink, Fusion Library, University of Wisconsin, USA

Institute for Plasma Research, University of Maryland, USA

Librarian, Fusion Energy Division, Oak Ridge National Laboratory, USA

Librarian, Institute of Fusion Studies, University of Texas, USA

Librarian, Magnetic Fusion Program, Lawrence Livermore National Laboratory, USA

Library, General Atomics, USA

Plasma Physics Group, Fusion Energy Research Program, University of California at San Diego, USA

Plasma Physics Library, Columbia University, USA

Alkesh Punjabi, Center for Fusion Research and Training, Hampton University, USA

Dr. W.M. Stacey, Fusion Research Center, Georgia Institute of Technology, USA

Dr. J ohn Willis, U.S. Department of Energy, Office of Fusion Energy Sciences, USA

Mr. Paul H. Wright, Indianapolis, Indiana, USA 
The Princeton Plasma Physics Laboratory is operated by Princeton University under contract with the U.S. Department of Energy.

\author{
Information Services \\ Princeton Plasma Physics Laboratory \\ P.O. Box 451 \\ Princeton, NJ 08543
}

Phone: 609-243-2750

Fax: 609-243-2751

e-mail: pppl_info@pppl.gov

Internet Address: http://www.pppl.gov 